\title{
A Introdução da gymnastica na Escola Normal de São Paulo (1890-1908) ${ }^{1}$
}

\author{
Edivaldo Gois Júnior * \\ José Carlos Freitas Batista **
}

\begin{abstract}
Resumo: Este estudo teve como objetivo compreender o contexto que possibilitou a inclusão da disciplina de Gymnastica no currículo da Escola Normal de São Paulo, bem como, as motivações e métodos dos professores no ensino da disciplina. $O$ estudo observou uma apropriação da Ginástica nas escolas liberais e laicas da Europa do século XIX, e uma crescente influência norte-americana na Escola Normal com os ideais pedagógicos de Caetano de Campos, houve uma reforma curricular, que em 1890, introduziu a Ginástica na Escola. Palavras-chave: História. Educação Física. Educação. Ginástica.
\end{abstract}

\section{INTRODUÇÃO}

No final do século XIX, a principal escola pública de São Paulo, a Escola Normal de São Paulo, posteriormente, renomeada Escola Normal Caetano de Campos, introduz em seu currículo a prática da Ginástica e dos Exercícios Militares, como disciplina dos normalistas, e atividade obrigatória das escolas primárias, anexas à Escola Normal. Nosso problema de pesquisa consiste em compreender o contexto que possibilitou esta inclusão, bem como, as motivações e métodos dos professores no ensino da Ginástica em São Paulo.

Em termos metodológicos, foi realizada uma pesquisa histórica, que levantou fontes primárias e secundárias. Os dados foram

\footnotetext{
*Professor Doutor em Educação Física. Universidade Nove de Julho e Universidade São Judas Tadeu. Consultor do Instituto Nacional de Estudos e Pesquisas Educacionais. São Paulo, SP, Brasil. E-mail: egoisjunior@gmail.com

**Professor Doutor em Educação. Diretor do Departamento de Educação da Universidade Nove de Julho (UNINOVE). São Paulo, SP, Brasil.. E-mail: jcfreitas@uninove.br ${ }^{1}$ Agradecimento especial à arquiteta Fabiana, funcionária do Centro de Referência em Educação, pelo cuidado com a memória da educação paulista.
} 
analisados a partir da perspectiva histórica de Paulo Veyne (1995), em que as fontes não se caracterizam como provas factuais, mas indícios que nos aproximam da realidade, mas não é a verdade em si. Deste modo, o trabalho do historiador consiste na possibilidade de narração de uma trama que é sustentada pelos dados empíricos. Analisamos as fontes primárias não como provas científicas, pois elas têm limites: "[...] enquanto houver historiadores, suas explicações serão incompletas, pois nunca poderão ser uma regressão ao infinito". (VEYNE, 1995, p.56). O centro da historiografia de Paul Veyne sustenta-se no conceito de que a história não tem anatomia, não constrói o passado em si, mas interpretações, uma narrativa sobre o passado. A historiografia deste artigo, ao analisar as fontes, parte desta prerrogativa, de construção de uma interpretação, limitada.

As fontes primárias foram coletadas no Arquivo Público Caetano de Campos, ligado ao Centro de Referência em Educação de São Paulo. Foram levantadas, em um recorte historiográfico (1890-1908), atas de reuniões, álbuns fotográficos, relatórios da direção, o periódico A Eschola Publica, que em 1902, tem o nome modificado para Revista de Ensino, títulos elaborados a partir das experiências dos professores da Escola Normal, publicados com verba pública do Estado de São Paulo (PINTO, 2008). As fontes comparadas à revisão de literatura desenharam, a partir da análise dos resultados, indícios que possibilitaram, nos termos de Paul Veyne (1995), uma trama na reconstituição do período (1890-1908), correspondente a primeira fase do ensino da ginástica na Escola Normal.

\section{Contextualização da escola}

Na primeira metade do século XIX, a organização da instrução pública no Brasil era muito precária. Com a vinda da família real portuguesa em 1808, inicia-se um precário investimento na educação (CASTANHO, 2004; ZOTTI, 2004; AZEVEDO, 1976), mas que infelizmente, priorizava a educação das elites em cursos superiores para a formação de profissionais liberais, ou o ensino secundá- 
rio na capital da corte, exemplificada pelo Collegio Imperial de Pedro Segundo (CUNHA JÚNIOR, 2008). Incapaz de organizar a educação popular e pública, o governo imperial, através do ato adicional de 1834, acrescentou na Lei da educação elementar de 1827, uma estrutura educacional dividida em três níveis: instrução primária, secundária e ensino superior, competindo às assembléias provinciais e aos seus governos executivos a responsabilidade sobre os dois primeiros níveis de instrução, e ao governo imperial a estruturação do ensino superior (ZOTTI, 2004). Desse modo, em 1834, o império abre mão do domínio político e administrativo sobre a instrução popular no país.

Em relação à Ginástica Escolar, Cunha Júnior (2003) descreve que o Colégio Pedro II, fundado em 1837 com o objetivo de oferecer uma formação diferenciada à elite carioca do século XIX, introduz no ensino público fluminense as práticas da Ginástica. Como colégio oficial se diferenciou com uma formação moderna que incluía em seu currículo saberes desconhecidos dos outros colégios, como a música, desenho e a própria ginástica. $\mathrm{O}$ aluno formado pelo colégio recebia o título de bacharel em Letras, e poderia ingressar em qualquer curso superior do país.

Seu primeiro professor de ginástica, em 1841, foi Guilherme Luiz de Taube, contrato pelo reitor Joaquim Caetano da Silva, médico formado em Paris, que foi convencido pelos argumentos higienistas de Taube a introduzir a ginástica no colégio. Outro argumento foi o fato dos melhores colégios europeus já terem adotado a prática de exercícios ginásticos. Com isso, foi fixado o salário de Guilherme de Taube em Quatrocentos mil réis, o menor salário do colégio, o que denota uma inferioridade da área em relação às outras disciplinas da escola. Além disso, ele não possuía o título de professor, era nomeado como mestre, um título inferior na época (CUNHA JÚNIOR, 2003).

A partir de 1835 (BUSCH, 1946), então, na província de São Paulo, iniciou-se o ideário de construção de uma Escola Normal, que teria o objetivo de formar o professorado paulista para a instrução primária na província. Contudo, apenas em 1843, apresentou-se 
à assembléia paulista, o projeto para sua criação, que foi aprovada através da Lei nº 34 de 1846.

A primeira fundação da escola mantinha um curso de dois anos, em que apenas um professor, o Sr. Manuel José Chaves, ministrava as disciplinas de Gramática e Língua Nacional, Aritmética, Religião, Geometria, Caligrafia, Lógica, todas as disciplinas que compunham o currículo das escolas primárias, exceto a disciplina de Métodos e processos de ensino, específica do Ensino Normal (ALMEIDA, 1995). O ensino era ministrado na Escola Normal apenas para o sexo masculino. Em 1847, foi fundada a seção feminina. A seção masculina funcionou até 1866 , formando apenas 40 professores (BUSCH, 1946). A escola foi reaberta em 1875, em prédio anexo à faculdade de Direito do Largo São Francisco, mas é fechada novamente em 1878.

Nessa primeira fase não foram encontrados indícios da prática de ginástica no contexto escolar. Ao estudarmos as atas e relatórios, não levantamos fontes primárias sobre a prática da ginástica. Ao contrário, como já descrevemos, do Collegio Imperial de Pedro Segundo, no Rio de Janeiro, que já havia organizado aulas desde 1841 (CUNHA JÚNIOR, 2003).

O panorama não foi modificado nessa primeira fase em que a escola não conseguia se consolidar na capital paulista. Contudo, a partir de 1880, Laurindo Abelardo de Brito, ex-aluno da Escola Normal, torna-se presidente da província de São Paulo. Com isso, em 1880, a escola é reaberta (BUSCH, 1946), e ventos de mudança sopram no país (NAGLE, 1974), e em São Paulo, por conseguinte, no final do século XIX,

\section{POSITIVISMO E MOVIMENTO REPUBLICANO}

No final do século XIX desenha-se um ideário que fortalecerá a consolidação da Escola Normal, e também, a prática dos exercícios físicos na escola.

O Positivismo, de uma forma sucinta, é entendido como método 
científico que afirmava que todo o axioma racional poderia ser explicado, justificado, por uma lógica experimental e matemática. As leis da ciência regem o mundo, fugindo de explicações espiritualistas. Comte substituía a religião pela Religião da humanidade, versão propalada pelo Positivismo de última instância. Thomas Skidmore (1998) afirma que o positivismo no Brasil foi absorvido mediante re-apropriações, ou seja, os brasileiros construíram sua própria leitura positivista, embora, sempre fizessem referência à figura de Comte, o principal líder do positivismo francês.

Em resumo, nas palavras de Skidmore (1998), o positivismo manteve uma forte, ainda que difusa, influência no Brasil, não por suas doutrinas detalhadas, mas por seu estilo intelectual - sobretudo pelo apelo a uma abordagem 'científica' para compreensão da sociedade e da história. (GÓIS JUNIOR, 2005)

É certo que esta corrente filosófico-doutrinária atraiu número crescente de jovens, oriundos das escolas de direito. Também, é correto afirmar que os professores de matemática e ciências exatas, agrupados nas escolas militares e na Escola Politécnica, em que se transformou a antiga Real Academia Militar, aderiam em massa às doutrinas de Comte. Desse modo, concebe-se a idéia de que a Educação Física como prática defendida pelos militares, logicamente, teria uma tradição positivista desde o século 19 , desde que nos círculos intelectuais do fim daquele século 19 e início do século 20, predominava o Positivismo no Brasil.

Os primeiros debates sobre o modelo de Educação Física a ser implantado no Brasil - sobretudo originados no Poder Legislativo embora envolvessem discussões científicas, não se restringiam a elas nem se resolviam no campo acadêmico. Muitas divergências surgidas com grande parte dos educadores civis e com a Igreja foram sempre resolvidas em um campo antes político que científico. Nesse contexto, evidencia-se o ecletismo de preposições políticas e científicas que marcam os defensores da Educação Física no Brasil. O Brasil no campo político, científico e cultural vivia-se em um ecletismo extremamente conciliador (CASTRO,1997).

Segundo Castro (1997) no século XIX os militares dividiam-se 
em dois grupos, os de baixa patente, sem nenhuma formação acadêmica e os oficiais "científicos", que eram formados pela Escola Militar da Praia Vermelha, onde o ensino predominante era o da matemática superior e das ciências, ao invés das matérias profissionais. De acordo com a mesma fonte, esses oficiais interessavam-se muito mais pela atuação política do que pela carreira, como demonstra a atuação de destaque que os "científicos" tiveram no golpe de 1889, nos primeiros anos da República e em diversas manifestações "florianistas".

O reflexo do positivismo militar, incentivando a prática da ginástica, como descreve Castro (1997), soma-se ao movimento republicano de orientação política liberal, e pelo positivismo, sobretudo pelos intelectuais oriundos da Escola de Direito do Largo São Francisco, em São Paulo, criam uma atmosfera anti-monarquia.

Em São Paulo, um dos principais ativistas do movimento republicano foi Rangel Pestana, que terá sua biografia atrelada indiretamente à nova Escola Normal de São Paulo.

Rangel Pestana chega a São Paulo em 1857, formou-se na Escola de Direito em 1863, na mesma turma de Campos Sales e Prudente de Morais. Em 1865, foi idealizador do jornal "Opinião Liberal", foi um dos fundadores do Partido Republicano em 1870. Em 1875 dirigiu o novo jornal "A província de São Paulo", periódico de propaganda republicana, até 1889, quando o Império é destituído, com a Proclamação da República. (CAMPOS, 1946).

Com essa biografia, e representatividade, em 1889, passa a compor o governo provisório do Estado de São Paulo ao lado de Prudente de Morais.

Quatro dias depois, no dia 19 de novembro de 1889, os professores da Escola Normal de São Paulo se reuniram, e fizeram questão, de fazer constar na ata de reuniões, seu apoio irrestrito ao governo republicano, e ao governo provisório do Estado de São Paulo, em seus termos:

Pedindo a palavra o professor Carlos Reis disse que de algum tempo ja tinha posto seus serviços e sua actividade á disposição da causa republicana 
que brilhante e victoriamente triumphou a quinze do corrente mes com a declaração do estabelecimento da Republica como forma de governo politico do Brasil, e que portanto claro era que a nova ordem de coisas, trazida por aquelle glorioso facto, e o Governo Provisório do Estado de São Paulo tinham a sua franca e sincera adhesão, seu franco e leal apoio...(sic) (ESCOLA NORMAL DE SÃO PAULO, Ata de Reunião, 19 de novembro de 1889)

A menção do professor Carlos Reis foi aprovada unanimemente por todo o corpo docente.

Naquele momento, os docentes não imaginavam que um médico renomado se tornaria Diretor na Escola Normal. Rangel Pestana usa sua influência e indica para o cargo de Diretor o médico Antônio Caetano de Campos, que assumiu o cargo no dia 18 de janeiro de 1890 (ESCOLA NORMAL DE SÃO PAULO, Ata de Reunião, 1890).

A história da vida acadêmica deste médico começa no Rio de Janeiro, ingressa no curso de Medicina da Corte, em 1862, para arcar as despesas, é professor no renomado Colégio Tautfoues, onde foi ex-aluno. No quinto ano do curso de medicina, presta concurso para docência no Colégio Pedro Segundo, e é reprovado. Forma-se em 1867, médico. Serve na Guerra do Paraguai, e em seu retorno é aconselhado por um professor a mudar-se para São Paulo. Chega à capital paulista em 1870. Além de exercer a medicina, Caetano de Campos torna-se professor no Colégio Pestana, onde conhece Rangel Pestana. Com este vínculo, Caetano de Campos passa a ser influenciado fortemente por Rangel Pestana, o que ocasiona, anos depois, sua nomeação, como Diretor da Escola Normal de São Paulo (ROCCO, 1946).

\section{Reforma Caetano de Campos (1890)}

Com sua posse, Caetano de Campos inicia uma grande remodelação na Escola, conhecida como Reforma Geral da Instrução Pública de São Paulo, aprovada em 12 de março de 1890. O ideário 
pedagógico desta reforma estabelecia-se, principalmente, pela influência teórica de Pestallozzi, e pelo modelo norte-americano (ALMEIDA, 1995). Desse modo, a nova estrutura curricular baseava-se no aprender fazendo, em atividades utilitárias. Para Casimiro dos Reis Filho (1981), Caetano de Campos tinha um ideário fortemente biológico sobre a realidade, amalgamado com convicções liberais. Um ideário bastante coerente com o contexto do final do século XIX, entre o liberalismo e o positivismo eclético brasileiro, como já descrevemos, anteriormente. Com isso, a Escola Normal de São Paulo, torna-se modelo republicano para outras escolas normais do país (SCHUELER; MAGALDI, 2009).

Interessa-nos, neste momento, o paralelo, que podemos realizar com os colégios protestantes em São Paulo, como por exemplo, o Collegio Mackenzie. Podemos perceber que Caetano de Campos, ao reformar a Escola Normal, convidou a professora Miss Marcia Brown, norte-americana, e professora do Collegio Mackenzie. A nova reforma na Escola Normal em 1890 espelhava-se nos colégios protestantes de São Paulo, e no próprio modelo de educação norteamericana (CAMPOS, 2005; MINARDI, 2003), que era perfeitamente coerente com as idéias de Rangel Pestana e Caetano de Campos. Segundo Almeida (2007, p. 335):

Intelectuais formadores de opinião como Rui Barbosa, Rangel Pestana, Caetano de Campos, entre outros, viam com simpatia essa forma de os protestantes veicularem sua cultura e moldarem sua identidade, e não foram poucos os que consideravam o "modelo cultural" norte-americano algo a ser seguido e implantado no país, que procurava organizar um sistema de ensino que o equiparasse às grandes nações do mundo.

Primeiramente, Caetano Campos, baseado nesse ideário, reformulou a estrutura curricular da Escola Normal, e também sua organização, introduzindo atividades práticas e utilitárias, como por exemplo, a Ginástica.A Escola Normal de São Paulo passou a ter o seguinte currículo, descrito nas atas de reunião de 1890: 
Primeiro Ano: Português; Aritmética; Geografia; Exercícios Militares (para a seção masculina); Prendas e Exercícios Escolares (para seção feminina); Caligrafia; Desenho.

Segundo Ano: Português; Álgebra e Escrituração Mercantil (seção masculina); Geometria; Física e Química; Ginástica, Música; Desenho, Economia Doméstica e Prendas (seção feminina)

Terceiro Ano: História do Brasil; Biologia; Educação Cívica e Economia Política; Organização das Escolas e Direção; Exercícios Práticos.

A partir deste currículo, os alunos-mestres, aplicavam seus ensinamentos em escolas-modelo, anexas à Escola Normal, que eram escolas primárias onde novas metodologias eram aplicadas, entre elas, a Ginástica e Exercícios militares.

Dessa forma, deu-se a introdução da Ginástica no currículo escolar da Escola Normal de São Paulo, uma escola criada para ser o modelo da instrução pública paulista. Nesse contexto, temos que compreender que sua prática ainda estava distante de outras escolas públicas primárias de São Paulo. Se a Ginástica foi introduzida em 1890, nas outras escolas primárias essa realidade era mais distante. A aula de Ginástica representava uma das prerrogativas de uma escola moderna, assim, seu acesso enfrentou grandes dificuldades na instrução pública paulista. Mas, enfim, quais eram os objetivos destas aulas? Como ocorriam? Existiu uma influência norteamericana, por exemplo, na introdução de esportes na Escola Normal, como pregava seu modelo? E a ginástica européia, com seu cientificismo, tão influente nas instituições militares, marcaria fortemente as aulas da Escola Normal?

\section{A gymnastica na escola nORMAl de São Paulo (1890-1908)}

A Escola Normal de São Paulo possuía, a partir de 1890, a disciplina de Gymnastica e Exercicios Militares. As aulas aconteciam duas vezes por semana para os normalistas, tanto na seção 
masculina, quanto na seção feminina. Contudo as mulheres não realizavam os exercícios militares, que eram substituídos na seção feminina por Prendas e Exercicios Escolares. Já nas escolas-modelo primárias anexas a Gymnastica estava presente do $1^{\circ}$ ao $5^{\circ}$ ano do currículo, na seção masculina, três vezes por semana. Com exceção do $4^{\circ}$ e $1^{\circ}$ anos: duas vezes por semana, e uma vez por semana, respectivamente. Na seção feminina, todos os anos realizavam as atividades três vezes por semana, exceto o $1^{\circ}$ ano, duas vezes por semana (ESCOLA NORMAL DE SÃO PAULO, RELATORIO DE DIRECÇÃO, 1895).

Havia na escola, no período estudado, dois professores de Ginástica, para a Seção Masculina o professor Baragiola (nenhum documento cita o primeiro nome), e na seção feminina, Maria Moratti. É interessante perceber que as fontes primárias coletadas no arquivo da escola, revelam que o tratamento recebido pelos mestres de ginástica era de professores, ao contrário, do Collegio Pedro Segundo, onde eram tratados como mestres (CUNHA JÚNIOR, 2003) no século XIX. Além disso, a disciplina possuía provas finais, o que a colocava em relação de igualdade com as outras. Como consta em ata de 30 de novembro de 1891:

Organisados e assim approvados os pontos para os exames finaes das diversa materias no curso normal, foram nomeadas as respectivas comissões examinadoras e julgadoras, que ficaram compostas do seguinte modo: $1^{\circ}$ anno: Exercicios Militares: C. Reis, Baragiola e F. Silveiro [...]. $2^{\circ}$ anno: Gymnastica: C. Reis, Baragiola e F. Silveiro (sic). (ESCOLA NORMAL DE SÃO PAULO, Ata de Reunião, 1891)

Se os professores de Ginástica recebiam o tratamento de professores, e a disciplina compunha os exames finais, a mesma valorização não ocorria nos salários. Segundo o "Orçamento das despezas da Escola Normal e Escola Modelo (1894)", havia uma desvalorização dos professores de ginástica em relação aos professores das cadeiras teóricas, chamados de lentes cathedraticos: 
[...] 19 lentes cathedraticos: 6:000\$000, total 114:000\$000

2 Professores de gymnastica: 3:600\$000, total 7:200\$000

2 Professores de trabalhos manuaes: 3:600\$000, total 7:200\$000

1 Professor de Escripturação Mercantil: 4:800\$000, total 4:800\$000

1 Professor de Musica: 4:800\$000, total 4:800\$000

1 Professor de Economia Domestica: 3:600\$000, total 3:600\$000 [...]

(ESCOLA NORMAL DE SÃO PAULO, RELATORIO DE DIRECÇÃO, 1894, p.96)

Fica evidente, a partir desta fonte, a desvalorização do trabalho professor de Ginástica. Embora a Escola compreendesse a importância na formação do alunado, isto não se refletia na valorização do profissional. Sobre a importância da ginástica, o periódico A Eschola Publica dá grande destaque a sua prática, aos exercícios fúsicos, e o ensino militar.

Em 1902, foi publicado um artigo de Carlos Gomes Cardin em que defendia a idéia de educação integral, usando os conhecidos argumentos do corpo como máquina que deve ser cuidada, ou mesmo, a idéia de mente sã em um corpo são:

O homem, a suprema obra da natura, o ser mais perfeito da série animal, a concentração de um mundo em miniatura, não é mais que um relogio artisticamente elaborado e genialmente combinado. As manifestações intellectuaes e Moraes são meramente physiologicas e portanto, conseqüências de um trabalho bem elaborado e de combinações extraordinarias de phenomenos inteiramente ligados. Si este conjuncto vital é harmonico como sóe manifestar-se, não se póde admittir um cérebro robusto em um corpo fraco, como não se póde admittir uma moral sã em um corpo doentil. [...] Havendo 
uma relação de dependencia mutua entre os diversos orgams formando os systemas, entre os diversos systemas formando os apparelhos, entre os diversos apparelhos formando o individuo, necessariamente o cerebro, como elemento dessa grande machina, será dependente do individuo. (CARDIM, 1902, p.396)

Se o discurso legitimador da Educação Física não parecia diferenciar os seus defensores, sempre utilizando os argumentos da educação integral, é na questão dos métodos que conseguimos perceber as diferenciações.

O professor Baragiola, responsável pelas aulas de Ginástica na Escola Normal de São Paulo no período estudado, nos mostra o quanto era polêmica a questão dos métodos ginásticos. Em artigo publicado na Revista de Ensino, nos dá vários indícios sobre as influências metodológicas que recebeu e que critica fortemente o método alemão:

A Gymnastica Escolar Moderna não tem por certo fim formar acrobatas, ou artistas de circo: ella foi introduzida nas escolas para desenvolver e fortalecer os organismos, em proveito do espirito e da vida pratica. [...] Foi o começo da lucta dos pedagogistas contra o abuso dos apparelhos gymnasticos, e a introducção dum systema mais racional, no qual os jogos ao ar livre deviam ter o principal logar. [...] O grande professor E. Paz, encarregado de estudar na Alemanha o ensino da gymnastica, manifesta-se contrario a muitos apparelhos que são o orgulho dos gymnasticos suissos e allemães. (BARAGIOLA, 1902, p. 256-7)

Para o professor a ginástica alemã tinha problemas, pois era perigosa para o alunado. Baragiola (1992) ainda cita sua admiração por Pestallozi, Ling, citando-os como grandes professores. Mas é da educação física norte-americana sua grande influência, pois ao mapear as aulas de ginástica no mundo, ele mostra como os jogos ao ar livre ganham importância. Contudo, no fim do artigo nos posiciona sobre o que deveria ser a ginástica escolar no Brasil: 
Qual será o systema a se adoptar nas escolas brazileiras? Os systemas adoptados pelas differentes nações nos ensinam como devemos seguir na marcha das innovações. $O$ caracter da gymnastica brazileira deve ser eminentemente educativa-militar, mas deve dar uma grande margem aos jogos ao ar livre. Um paiz que não tem o serviço militar obrigatorio, deve dar esse ensino nas escolas, e isso só se póde obter com uma gymnastica militar bem dirigida. Não só conhecendo as evoluções militares que um alumno será um bom guardanacional; é sabendo manejar com facilidade uma carabina, que o alumno terá obtido um bom resultado physico. Para isso precisa o concurso da gymnastica, para que elle possa supportar o peso da arma, e dos jogos ao ar livre para que ele possa resistir ás marchas. (BARAGIOLA, 1902, p. 259)

$\mathrm{Na}$ iconografia levantada nesta pesquisa foram coletadas 61 fotografias sobre as aulas de ginástica que datam entre 1895 e 1908. Nelas podemos constatar uma coerência entre o discurso de Baragiola na Revista de Ensino e a prática das aulas. Em relação aos conteúdos ministrados pelo professor, podemos identificar uma variedade de atividades, entre elas: Ginástica Geral, Ginástica com aparelhos, Jogos ao ar livre, Basquetebol, Corridas, Saltos, Salto com vara, Esgrima, Cantigas de Roda, Tiro, Exercícios Militares, Cabo de guerra, e marchas. Embora, devemos compreender que a fotografia era um evento especial na virada do século XIX para o XX, assim o professor selecionava o que desejaria aparecer, e não, necessariamente o cotidiano da escola. Embora a imagem como fonte tenha essa limitação, nos fornece indícios importantes sobre a prática da Ginástica na Escola Normal.

Podemos ainda observar que as aulas a partir de 1894, eram ministradas na própria sala de aula, em uma sala de ginástica de aparelhos, e a grande maioria das atividades fotografadas eram executadas ao ar livre no pátio da nova escola, inaugurada em 1894. O suntuoso prédio foi construído na atual Praça da República em São Paulo, um projeto do mesmo arquiteto do Teatro Municipal de São Paulo, Ramos de Azevedo. Hoje é sede da Secretaria de Educação do Estado de São Paulo. 


\section{CONSIDERAÇÕES FINAIS}

Podemos identificar neste artigo uma consonância entre o ideário republicano, o positivismo de caráter eclético no Brasil, com os ideais e a prática pedagógica liberal da Escola Normal de São Paulo. Como existia também uma apropriação da ginástica nas escolas liberais e laicas da Europa do século XIX, e uma crescente influência norte-americana na Escola Normal com os ideais pedagógicos de Caetano de Campos, houve uma reforma curricular, que em 1890, introduziu a ginástica na Escola Normal de São Paulo. Já em 1894 a inauguração do novo prédio na Praça da República criou a estrutura necessária para o desenvolvimento da cadeira de Ginástica na Escola Normal.

Compreendemos que a descrição histórica da ginástica na Escola Normal não refletia a realidade do ensino da disciplina em outras escolas paulistas porque ela era o modelo ideal de educação pública de São Paulo, e não a realidade do ensino paulista. Contudo, sugerimos para futuros estudos e por considerarmos importante, verificar a influência dos alunos normalistas formados como professores nas escolas primárias e complementares no início do século $\mathrm{XX}$.

The introduction of gymnastic in the Sao Paulo
normal school (1890-1908's)
Abstract: This study aimed understands the context
which enabled inclusion of Gymnastic in curriculum of
Sao Paulo Normal School and, motivations and
methods in teaching the discipline. The study noted an
appropriation of Gymnastics in European liberals
schools in 19th century. There an increasing American
influence in Sao Paulo Normal School, and with the
ideals pedagogical of Caetano de Campos was
reformed the curriculum in 1890's, introducing the
Gymnastic in school.
Keywords: History. Physical Education. Education.
Gymnastic.




\begin{tabular}{l}
\hline La introducción de gimnasia en la escuela nor- \\
mal de Sao Paulo (1890 a 1908) \\
Resumen : Este estudio fue comprender el contexto \\
que permitió la inclusión de la disciplina de Gimnasia el \\
plan de estudios de la Escuela Normal de Sao Paulo, \\
así como las motivaciones y los métodos de los maes- \\
tros en la disciplina. El estudio constata una \\
consignación de gimnasia en las escuelas liberales \\
del siglo XIX en la Europa, y una creciente influencia \\
norteamericana en la Escuela Normal con los ideales \\
de la enseñanza de Caetano de Campos, que consolidó \\
una reforma curricular que introdujo la Gimnasia en el \\
año 1890. \\
Palabras Clave: Historia. Educación Física. \\
Educación. Gimnasia.
\end{tabular}

\section{REFERÊNCIAS}

ALMEIDA, Jane Soares de. Currículos da Escola Normal Paulista (1846-1920): revendo uma trajetória. Revista Brasileira de Estudos Pedagógicos, Brasília, v.76, n. 184, p.665-89, 1995.

- Missionárias norteamericanas na educação brasileira: vestígios de sua passagem nas escolas de São Paulo no século XIX. Revista Brasileira de Educação, v. 12, p. 327-342, 2007.

AZEVEDO, Fernando de. A transmissão da cultura. São Paulo, Melhoramentos, 1976.

BARAGIOLA, M. Gymnastica Moderna. Revista de Ensino, São Paulo, v. 1, n.2, p.256-9, 1902.

BUSCH, Reynaldo Kuntz. Evolução e organização atual do Ensino Normal de São Paulo. In: ROCCO, Sebastião. (Org.). Poliantéia do centenário. São Paulo, Governo do Estado, 1946.

CAMPOS, Judas Tadeu. As políticas de formação dos professores paulistas antes, durante e depois da pedagogia tecnicista. Revista E-Curriculum, São Paulo, v. 1, n. 1, p.1-14, 2005.

CAMPOS, Moacyr. Rangel Pestana. In: ROCCO, Sebastião. (Org.). Poliantéia do centenário. São Paulo: Governo do Estado, 1946.

CARDIM, Carlos Gomes. O exercicio physico. Revista de Ensino, São Paulo, v. 1, n.1, p.395-400, 1902.

CASTANHO, Sérgio E.M.. A educação escolar pública e a formação de professores no Império Brasileiro. In: LOMBARDI, José Claudinei; NASCIMENTO, Maria Isabel

Vovimento, Porto Alegre, v. 16, n. 03, p. 71-87, julho/setembro de 2010. 
Moura, (Orgs.). Fontes, história e historiografia da educação. Campinas, Autores Associados, 2004. p.37-64.

CASTRO, Celso. Os militares e a introdução da educação física no Brasil. Antropolítica, Niterói, v.2, p.61-78, 1997.

CUNHA JUNIOR, C.F. Os exercícios gymnasticos no Collegio Imperial de Pedro Segundo (1841-1870). Revista Brasileira de Ciências do Esporte, Campinas, v. 25, n.1, p.69-81, set. 2003.

O imperial Collegio de Pedro II e o ensino secundário da boa sociedade brasileira. Rio de Janeiro, Apicuri, 2008.

ESCOLA NORMAL DE SÃO PAULO. Atas de Reunião. São Paulo: Escritos de Bico de Pena, 1889-1895.

ESCOLA NORMAL DE SÃO PAULO. Relatorio de Direcção. São Paulo: Typografia do Diario Official, 1894.

ESCOLA NORMAL DE SÃO PAULO. Relatorio de Direcção. São Paulo: Typografia do Diario Official,1895.

GOIS JUNIOR, E. Conhecimento Positivista da Educação Física e Esporte. In: DaCOSTA, L.P. Atlas do Esporte no Brasil. Rio de Janeiro, Shape, 2005. p.717718.

MINARDI, Inês. A contribuição educacional das missionárias norte-americanas na cidade de São Paulo. Revista Mackenzie Educação, Arte e História da Cultura, São Paulo, v. 3, n. 3, p. 141-147, 2003.

NAGLE, Jorge. Educação e Sociedade na Primeira República. São Paulo: EPU, 1974.

PINTO, Adriana Aparecida. Contribuições da Imprensa periódica especializada para os estudos em História da Educação: a revista A Eschola Publica e as disputas pela hegemonia do campo educacional paulista (1893-1897). Fronteiras, Dourados, v. 10, n. 18, p. 95-118, 2008.

REIS FILHO, Casimiro. A educação e a ilusão liberal. São Paulo, Cortez, 1981.

ROCCO, Salvador. Dr. Antônio Caetano de Campos. In: ROCCO, Sebastião (Org) Poliantéia do centenário. São Paulo, Governo do Estado, 1946.

SCHUELER, A. F. M. ; MAGALDI, Ana Maria . Educação escolar na Primeira República: memória, história e perspectivas de pesquisa. Tempo, Revista do Departamento de História da UFF, Niterói, v. 26, p. 32-55, 2009.

SKIDMORE, Thomas. Uma história do Brasil. Rio de Janeiro: Paz e Terra, 1998. 
VEYNE, Paul. Como se escreve história. Brasília, Editora da Universidade de Brasília, 1995.

ZOTTI, Solange A. Sociedade, educação e currículo no Brasil: dos jesuítas aos anos de 1980. Campinas: Autores Associados, 2004.

Recebido em: 26.11.2009

Aprovado em: 24.04.2010.

Wovimento, Porto Alegre, v. 16, n. 03, p. 71-87, julho/setembro de 2010. 